\title{
The use of lichens in post-smelting dumps reclamation - preliminary results of experimental cultivation of selected species on slag substrate
}

\author{
Kaja Rola ${ }^{1}$ and Piotr Osyczka ${ }^{1, *}$ \\ ${ }^{1}$ Jagiellonian University, Institute of Botany, Kopernika 27, 31-501 Kraków, Poland
}

\begin{abstract}
Conventional reclamation interventions of post-smelting slag dumps being undertaken so far either failed or produced poor results. Certain lichens, especially of the genus Cladonia, are known as effective colonisers of bare ground in anthropogenic habitats. The paper presents preliminary results of the experiment aimed at the evaluation of lichen usefulness in reclamation interventions. The cultivation in vivo involving transplantation of lichens directly on slag substrate was established in 2015. Five species, i.e. Cladonia rei, C. cariosa, C. pyxidata, C. subulata, C. macilenta, were transplanted into 32 cuvettes filled with sterilised slag substrate. The sample weight of 2 and $6 \mathrm{~g}$ were used and half of cuvettes were regularly supplied with $2 \%$ malt solution. The first important symptoms at the present stage of the experiment are as follow: the growth of thalli has appeared only in the case of first three species; $C$. rei shows the most effective development; cuvettes with $6 \mathrm{~g}$ sample weight are characterized by higher coverage of fresh lichen thalli; lichen biomass are visually higher in cuvettes treated with malt solution. The results give us reason to believe that lichens could be successfully used as an alternative element during planning of slag dumps reclamation in the future.
\end{abstract}

\section{Introduction}

\subsection{Environmental problems of post-industrial dumps}

Mining and heavy industry have substantially transformed the landscape and contaminated the environment. Large quantities of wastes have been deposited in post-industrial areas as dumps. According to the origin and chemical properties, the dumps associated with the extraction of zinc and lead ores can be generally divided into three main types $[1,2]$ : postmining dumps which constitute a mixture of dolomites, limestone, clays, sands and gravels, post-flotation dumps with a flotation sludge and finely ground dolomite, and post-smelting dumps consisting of slag from blast and muffle furnaces composed of dolomite crumbs, sinter slag, coke residue, $\mathrm{Pb}$-rich and $\mathrm{Zn}$-rich wastes. The latter dumps represent completely

\footnotetext{
${ }^{*}$ Corresponding author: piotr.osyczka@uj.edu.pl
} 
artificial environment characterised by extreme concentrations of toxic elements and highly adverse habitat conditions $[1,3]$. Due to high toxicity, they have negative impact on the surrounding environment and human health and constitute a serious problem requiring solution in many countries, particularly those with intensive industrial development and using primitive metal-ores processing technologies. Although in recent years metal industry has been reduced and/or modernised in Poland, many dumps remain in the landscape of Upper Silesia and are still partly exploited. The necessity of reducing the negative impacts on the local environment and indigenous populations cause the need for reclamation interventions. Regrettably, previous efforts toward natural compensation either failed or produced poor results in case of dangerously toxic slag dumps.

\subsection{Lichens as pioneer organisms}

Lichens (lichenized fungi) constitute a symbiotic association composed of two units, a lichen-forming fungus (mycobiont) and an alga and/or a cyanobacterium (photobiont), forming a combined organism. Compared with autonomic fungi, lichens have many peculiar features, of which the most important are distinct and highly variable morphology and anatomy, specific metabolic pathways, and exclusive methods of reproduction. Lichens occur at all latitudes and grow on almost any type of substrate. The structure and physiology of lichens decide their success in the colonisation of environments extremely hostile to life [4]. Lichens have been defined as stress tolerators [5] and they are effective and rapid colonisers of bare ground [6] Their pioneer nature is associated not only with natural sites characterised by harsh climate conditions, but also with anthropogenic and strongly affected habitats. There are various adaptation mechanisms facilitating successful colonisation of such areas (see e.g. [7]). Some epigeic lichens with modest ecological requirements are known to be the first and most important colonisers of contaminated substrates [8-11] (Fig. 1).
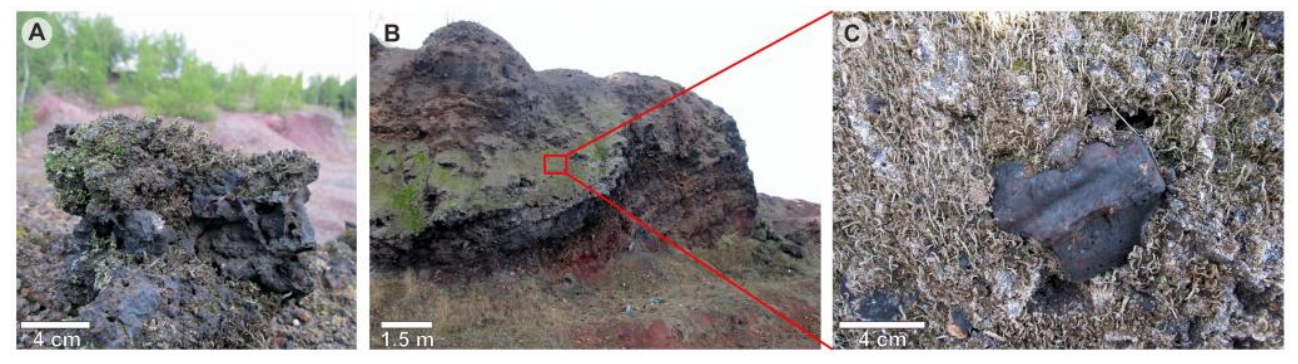

Fig. 1. Post-industrial wastes with associated lichens. A - solid sinter slag overgrown by the most resistant lichens; B - initial stage of succession of post-smelting dump with lichens as the first colonisers; $\mathbf{C}$ - dense sward of lichen assemblage covering slag substrate.

\subsection{Ecological role of lichens in spontaneous succession of post-smelting dumps}

The natural regeneration of post-smelting dumps is extremely sluggish. The process begins from artificial and sterile habitat and progresses towards the poorly developed xerothermic grasslands. The initial stages of succession are completely devoid of vascular plants, whereas cryptogamic organisms, mainly lichens and mosses, constitute the main visual component of vegetation $[8,11]$. The evidences have been provided that certain lichens are indifferent to extreme contamination and thus they are well adapted to slag substrate [9]. 
The spontaneous and rapid appearance of lichens in the initial successional stages of affected sites should be regarded as a positive phenomenon crucial for gradual and finally stable plant colonisation. They initiate physical weathering of solid slags and accelerate the natural process of soil formation, consolidation of the upper substrate layer and stabilization of the slopes (Fig. 1). Because of immense hygroscopic properties of thalli, lichens retain water droplets and atmospheric vapour, which improves local moisture conditions. Moreover, lichens act as providers of organic matter and fixed nitrogen, and therefore, they contribute to the fertility of the substrate [4].

\subsection{The purpose of the experiment}

It has been already postulated that the natural lichen cover should be taken into account when reclamation activities at post-smelting dumps are planned [9]. In relation to this problem, the purpose of our experiment is to evaluate the possibility of practical use of lichens in reclamation interventions aimed at accelerate the process of spontaneous regeneration of dumps. To accomplish this, we transplanted lichen thalli of selected species onto sterilized slag substrate and culture them in vivo.

\section{Materials and methods}

\subsection{Lichen species selected for experimental cultivation}

Lichens from the genus Cladonia are involved in the experiment. Certain representatives of the genus occur frequently on post-smelting dumps, achieve high coverage and frequently grow lushly forming dense swards [12]. Generally, these lichens as a rule consist of two kinds of thalli: a primary thallus in the form of horizontal squamules and vertical secondary thalli, called podetia. The occurrence of Cladonia lichens within metal-enriched areas has been frequently documented $[6,9,12,13]$. Fruticose form of growth and relatively high biomass of Cladonia cause that some of them appear to be the most effective colonisers of post-smelting dumps.

Specifically, we selected five species: Cladonia rei Schaer., C. cariosa (Ach.) Spreng., C. pyxidata (L.) Hoffm., C. subulata (L.) F. H. Wigg., C. macilenta Hoffm. All of them are common in Poland and have a high ability to vegetative reproduction enabling efficient propagation. The first three species have special ability to grow in highly contaminated habitats [14-16] and thus are considered as successful and rapid colonisers of highly disturbed habitats $[8,11]$. They constitute the major component of specific cryptogamic assemblages on post-smelting dumps in Poland [12] (Fig. 1). Lichen thalli intendent for transplantation were collected both from slag dump and adjacent semi-natural habitat. The latter two species, i.e. C. subulata and C. macilenta, are confined to open and sunny habitats. These lichens do not appear on slag dumps; however, they are associated with psammophilous grasslands in anthropogenic areas [10].

\subsection{Experiment design and procedure}

The cultivation in vivo experiment involving transplantation of lichens directly on slag substrate gives us the opportunity to recognize natural potential for growth of lichen thalli under stress conditions. The cultivation has been established in the Botanical Garden of the Jagiellonian University (Kraków) in 2015. The slag substrate was obtained from various parts of post-smelting dump in Ruda Śląska town. The chemical properties of the substrate are provided in Table 1. 
Table 1. Selected chemical properties of slag substrate used in the experiment (based on own earlier studies: $[9,11,14])$; min and max determined values are given.

\begin{tabular}{|c|c|c|c|c|c|c|c|c|}
\hline \multirow[b]{3}{*}{ Min } & \multicolumn{8}{|c|}{ Concentration of heavy metals ( $\mu \mathrm{g} / \mathrm{g}$; total and exchangeable forms) } \\
\hline & $\mathbf{Z n}_{\text {tot }}$ & Pbtot & Cdtot & & & $\mathbf{Z n}_{\mathbf{e}}$ & $\mathbf{P b}_{\text {ex }}$ & Cdex \\
\hline & 60766 & 20050 & 21.1 & & & 785 & 3932 & 1.93 \\
\hline Max & 99721 & 22845 & 90.3 & & & 817 & 4340 & 2.14 \\
\hline \multirow[b]{3}{*}{ Min } & \multicolumn{8}{|c|}{ Acidity and nutritional elements content } \\
\hline & $\mathbf{p H}(\mathrm{KCl})$ & $\mathbf{C}_{\text {org }}(\%)$ & \multicolumn{2}{|c|}{$\mathbf{N}_{\text {tot }}(\%)$} & \multicolumn{2}{|c|}{$\mathbf{K}(\mu \mathrm{g} / \mathrm{g})$} & $\mathbf{M g}(\mu \mathrm{g} / \mathrm{g})$ & $\mathbf{C a}(\mu \mathrm{g} / \mathrm{g})$ \\
\hline & 6.39 & 3.75 & \multicolumn{2}{|c|}{0.076} & \multicolumn{2}{|c|}{931} & 14068 & 7975 \\
\hline Max & 6.48 & 4.24 & \multicolumn{2}{|c|}{0.080} & \multicolumn{2}{|c|}{960} & 14519 & 8281 \\
\hline
\end{tabular}

The material was sterilised in $180^{\circ} \mathrm{C}$ for 24 hours to exclude the presence of any live propagules. Subsequently, the substrate was placed into 32 cuvettes of $38 \times 24 \times 7 \mathrm{~cm}$. Lichen thalli of all selected species were powdered into the form of propagules, which were evenly scattered on the substrate surface. The sample weight of 2 and $6 \mathrm{~g}$ were used. Half of the cuvettes have been regularly, i.e. once a week, supplied with $2 \%$ malt solution for potential support of fungal hyphae growth. The arrangement of cuvettes with lichen material are demonstrated on Fig. 2.
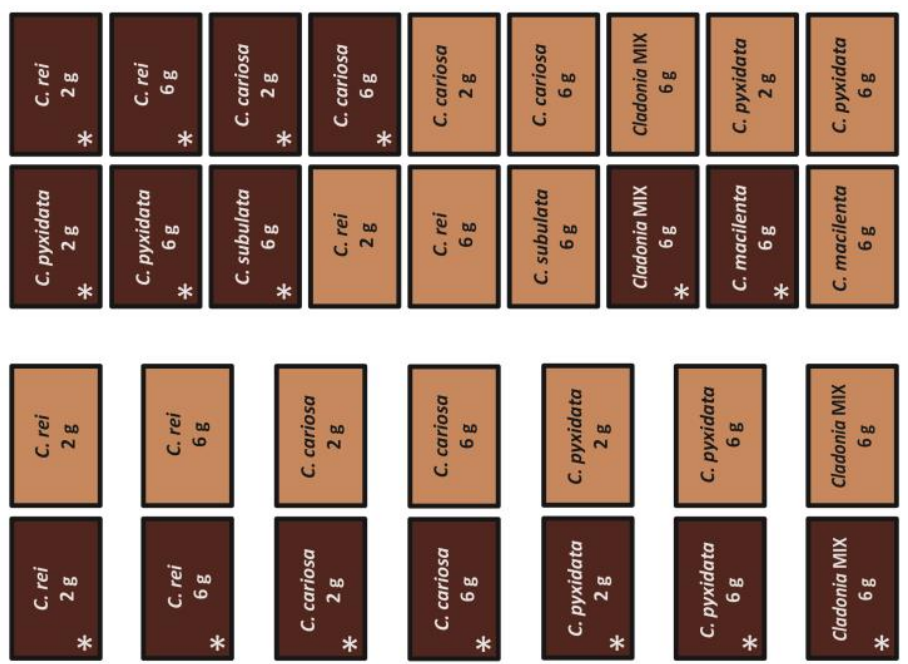

MIX - mixture composed of powdered C. rei, C. cariosa, C. pyxidata, C. subulata and C. macilenta lichen thalli * - cuvettes supplied with $2 \%$ malt solution

Fig. 2. Schematic layout of cuvettes in the cultivation experiment. The information on lichen species, sample weights and malt treatment are provided.

\section{Preliminary results}

The first symptoms of lichen thalli re-growth were observed half year after propagules transplantation (Fig. 3). At the present stage, one and a half year after the beginning of the experiment, regenerated thalli occur in the cuvettes with C. rei, C. cariosa, C. pyxidata and 
mix of Cladonia. Generally, cuvettes with $6 \mathrm{~g}$ sample weight are characterized by higher coverage of fresh lichen thalli compared to the cuvettes with $2 \mathrm{~g}$; however, in the case of $C$. rei these differences become less apparent over time.
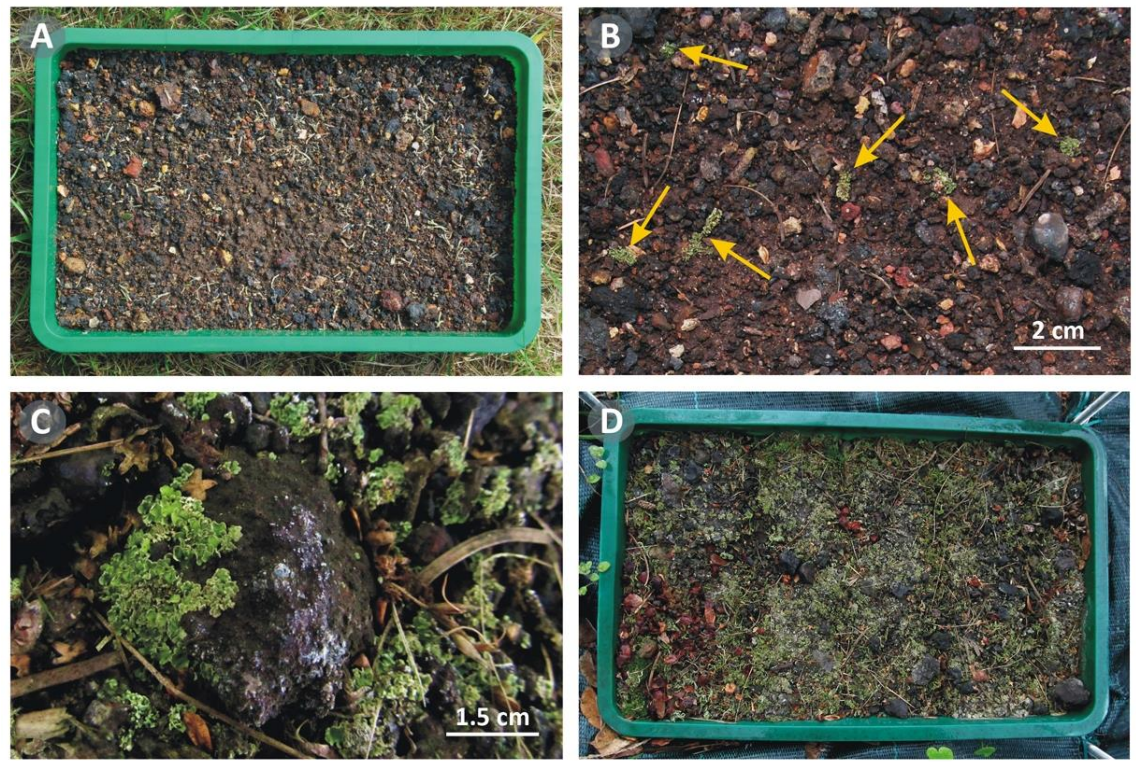

Fig. 3. The experiment of Cladonia lichens cultivation on slag substrate. $\mathbf{A}$ - the cuvette with scattered lichen propagules at the initial stage of cultivation; $\mathbf{B}$ - development of Cladonia rei primary squamules observed after six months from the beginning of experiment; $\mathbf{C}$ - colonization of solid sinter slag by Cladonia primary squamules in the cuvette; $\mathbf{D}$ - compact cover of C. rei in the cuvette after one and a half year.

The application of malt solution considerably improved lichen re-growth. Considering the samples with the same species and sample weight, the coverages of fresh lichen thalli are always higher in the cuvettes treated with this solution compared to those untreated (Table 2).

Table 2. Maximum coverage of lichen thalli in the cuvettes after 1.5 year of the experiment.

\begin{tabular}{|l|c|c|c|c|}
\hline & \multicolumn{2}{|c|}{ sample weight 2 g } & \multicolumn{2}{c|}{ sample weight 6 g } \\
\hline & $\begin{array}{c}\text { without malt } \\
\text { solution }\end{array}$ & $\begin{array}{c}\text { with malt } \\
\text { solution }\end{array}$ & $\begin{array}{c}\text { without malt } \\
\text { solution }\end{array}$ & $\begin{array}{c}\text { with malt } \\
\text { solution }\end{array}$ \\
\hline Cladonia rei & $28.31 \%$ & $43.28 \%$ & $17.87 \%$ & $45.03 \%$ \\
\hline Cladonia cariosa & $5.12 \%$ & $12.42 \%$ & $6.15 \%$ & $34.73 \%$ \\
\hline Cladonia pyxidata & $18.63 \%$ & $29.18 \%$ & $20.55 \%$ & $41.47 \%$ \\
\hline Cladonia macilenta & - & - & $0 \%$ & $0 \%$ \\
\hline Cladonia subulata & - & - & $0 \%$ & $0 \%$ \\
\hline Mix of Cladonia & - & - & $8.52 \%$ & $24.34 \%$ \\
\hline
\end{tabular}


Cladonia rei demonstrates the most effective development since regardless of sample weight and treatment its coverage in cuvettes are the highest among all tested species. Moreover, only in case of this species secondary thallus development has been already observed after one year and at the moment numerous podetia are present in the cuvettes. In contrast to these three aforementioned lichens, the thalli of $C$. macilenta and C. subulata showed no signs of regeneration. These results are additional argument that $C$. rei, $C$. cariosa and $C$. pyxidata are well adapted to extremely contaminated slag substrate and their occurrence on the dumps is not accidental. In case of cuvettes with assemblage of Cladonia only squamules of primary thallus have been developed till now. Therefore unambiguous determination of the material is not possible at this moment.

\section{Discussion}

Environmental rehabilitation of disturbed sites is a challenge facing the heavy-metal industry worldwide. Low levels of nutrients and organic matter, $\mathrm{pH}$ extremes, contamination and often difficult microclimatic conditions all hinder revegetation of postsmelting dumps. The most alarming are enormous contents of heavy metals which often can be detected on a percentage scale rather than at a trace level (see Table 1). Additionally, dark colour of the substrate contributes to accumulation of heat and high temperature amplitudes, which makes slag dumps extremely unfavourable for vegetation [3]. Therefore, the colonisation and natural regeneration of the considered dumps is extremely sluggish. Moreover, steep and unstable slopes of dumps additionally hinder reclamation treatments performed using conventional techniques. Our several previous studies showed that lichens play a fundamental role as effective pioneers in the initial stage of succession [9-12]. Consequently, lichen swards should be considered as an essential stage of succession, without which the development of stable plant cover would not be possible. We believe that the pioneering nature and unique adaptability to the contaminated substrate of certain Cladonia species could find practical application in reclamation interventions of slag dumps.

The results of earlier reclamation attempts confirm the need to search unconventional working methods. The support of plant cover development on post-smelting dumps only by means of 'rapid greening' that relied on sowing and planting mixtures of grasses, legumes and trees taxa either failed or resulted in a poor effect. Initially, such procedure seemed to be effective but after several years the intended effect of phytostabilization was not achieved. The patches of upper soil substrate slid of the slope under the influence of rainfall and erosion and this consequently led to uncovering the contaminated slag again $[3,17]$. More radical methods of remediation, theoretically possible to adapt, are practically sporadically used, because of the large size of the dumps and enormous costs related to implementation. Considering the problem in the long term, it can be observed that the most stable and diverse plant cover has developed on these fragments of dumps without any human influence.

Recent studies show that the spontaneous succession of insensitive or resistant to contamination species is in fact the most effective form of restoring the functionality of degraded habitats [18]. Natural regeneration often prevails over sophisticated and costly technical reclamation as species that are naturally well adapted to local habitat conditions do not require subsequent treatments to maintain their population. Compact cover of pioneer cryptogams is a very important element during restoration process $[11,19]$. Initiation and acceleration of succession processes at its earliest stages may prove to be an ecologically appropriate way of ecosystem restoration of strongly disturbed habitats. 


\section{Conclusions}

Lichens have not been considered as an useful biological tool in reclamation of areas degraded by heavy metal industry so far. Since certain species spontaneously colonize such areas and frequently constitute compact cover in the initial stage of succession, it seems to be reasonable take them into account when reclamation intervention are planned. The recognition of the potential for spontaneous regeneration of lichen thalli on slag substrate is the first step necessary for future unconventional remediation practices. This can be of particular importance in case of steep slopes of slag dumps on which the colonisation of vascular plants are nearly impossible even after several decades after end of wastes deposition. Our preliminary observations (Fig. 3) give us reason to believe that lichens could be successfully used as an alternative element during planning of slag dump reclamation in the future.

\section{References}

1. F. Maciak, Ochrona i rekultywacja środowiska (Szkoła Główna Gospodarstwa Wiejskiego, Warsaw, 1996)

2. World Bank Group, Pollution Prevention and Abatement Handbook 1998. Toward Cleaner Production (The International Bank for Reconstruction and Development/The World Bank, Washington, 1999)

3. K. Skubała, Arch. Environ. Prot. 37, 55-74 (2011)

4. T. H. Nash III, Lichen biology (Cambridge University Press, Cambridge, 2008)

5. J. P. Grime, Plant Strategies and Vegetation Processes (Wiley, Chichester, 1979)

6. O. Gilbert, Lichenologist 22, 87-101 (1990)

7. M. Bačkor, S. Loppi, Biol. Plantarum 53, 214-222 (2009)

8. D. Cuny, F. O. Denayer, B. de Foucault, R. Schumacker, P. Colein, C. van Haluwyn, Environ. Pollut. 129, 289-297 (2004)

9. P. Osyczka, K. Rola, Cent. Eur. J. Biol. 8, 876-887 (2013a)

10. K. Rola, P. Osyczka, Environ. Monit. Assess. 186, 5897-5910 (2014)

11. K. Rola, P. Osyczka, M. Nobis, P. Drozd, Ecol. Eng. 75, 332-342 (2015)

12. K. Rola, P. Osyczka, M. Nobis, Herzogia 27, 121-135 (2014)

13. O. W. Purvis, C. Halls, Lichenologist 28, 571-601 (1996)

14. Osyczka, K. Rola, Environ. Sci. and Pollut. R. 20, 5076-5084 (2013b)

15. P. Osyczka, K. Rola, A. Lenart-Boroń, P. Boroń, Cent. Eur. J. Biol. 9, 579-591 (2014)

16. P. Osyczka, K. Rola, K. Jankowska, Ecol. Indic. 61, 766-776 (2016)

17. B. Tokarska-Guzik, A. Rostański, Natura Silesiae Superioris, Suppl. 2001, 5-18 (2001)

18. K. Prach, R. J. Hobbs, Restor. Ecol. 16, 363-366 (2008)

19. K. Prach, Appl. Veg. Sci. 6, 125-129 (2003) 